\title{
Does Mycobacterium avium subspecies paratuberculosis cause Crohn's disease?
}

\section{R Balfour Sartor}

\section{Reassessing this persistent theory in light of advances in molecular microbial detection and genetic pathogenesis of disease}

S imilarities between chronic idiopathic granulomatous ileocolitis and mycobacterial infections have been noted since the original descriptions of the clinical syndrome now called Crohn's disease. ${ }^{1-4}$ Interest in a possible infectious origin of this disorder was renewed in 1989 when Chiodini et al cultured apparently identical Mycobacterium avium subspecies paratuberculosis (MAP) from three patients with Crohn's disease. ${ }^{5}$ This controversy increased in intensity following the detection of the specific DNA insertion sequence, IS900, of MAP in relatively high numbers of patients with Crohn's disease relative to ulcerative colitis and normal controls, ${ }^{6}$ and is now raging as several different groups have detected this organism in the food chain ${ }^{7}$ and water supply, ${ }^{8}$ proposed maternal-fetal transmission in human milk, ${ }^{9}$ reported long term responses to antimycobacterial antibiotic combinations, ${ }^{10}$ and even cultured viable $M$ paratuberculosis in blood samples of Crohn's disease patients. ${ }^{11}$

Additional data to support an association of MAP with Crohn's disease is provided by Autschbach and colleagues $^{12}$ in this issue of Gut (see page 944). This carefully performed and well controlled study used nested polymerase chain reaction (PCR) to detect the IS900 insertion element of MAP in 52\% of Crohn's disease resected tissues versus $2 \%$ of ulcerative colitis and $5 \%$ of mostly non-inflammatory control tissues. This study provides novel data regarding the prevalence of MAP in various phenotypes of Crohn's disease by showing slightly higher detection of IS900 DNA in colonic $(66.7 \%)$ compared with distal ileal $(40.5 \%)$ tissues and decreased detection rates with corticosteroid use. In addition, these authors reported weak associations with perianal involvement and a shorter duration of disease but no correlation with patient sex, age at diagnosis, stricturing versus penetrating phenotype, or presence of granulomas.
Data from this study help address some of the controversies that have fuelled the vigorous debate between committed advocates and confirmed sceptics that is receiving increasing attention in the scientific literature, lay press, and internet chat rooms. The arguments in favour or opposed to this theory (table 1) have some merit but many are flawed by incomplete data and lack of rigorous reflection. There is no doubt that a potential source of zoonotic infection exists, with widespread MAP infections in the dairy herds of Europe, North America, and Australia, ${ }^{13}{ }^{14}$ excretion of MAP in milk from infected cows, ${ }^{15}$ relative resistance of intracellular MAP to widely used pasteurisation techniques, ${ }^{16}$ and recovery of viable MAP from the water supplying Los Angeles. ${ }^{8}$ Moreover, the vast majority of studies using diverse techniques have detected MAP DNA or cultured this organism in higher frequency from tissues of patients with Crohn's disease than from those with ulcerative colitis and other disorders, although the reported frequency of recovery in both Crohn's disease and ulcerative colitis have ranged from $0 \%$ to $100 \% .{ }^{17}$ These results are consistent with two possibilities: either MAP infection could cause Crohn's disease in a subset of patients that are either selectively exposed to this organism or who are genetically susceptible to infection or, alternatively, this relatively common dietary organism may selectively colonise (or a dead organism selectively lodge in) the ulcerated mucosa of Crohn's disease patients but not initiate or perpetuate intestinal inflammation. Molecular fingerprints show that genotypes of bovine and human isolates are not similar but instead indicate that human and ovine (sheep) strains are more closely related. ${ }^{18}$ Maternal/fetal transmission of MAP has been proposed following culture of MAP from breast milk of two patients with Crohn's disease. ${ }^{9}$ However, the frequency of positive cultures in human milk is uncertain, this observation has not been replicated by other investigators, and there is no evidence of increased frequency of Crohn's disease in the offspring of mothers versus fathers with Crohn's disease. Even if transmission of viable MAP occurs, a plausible mechanism of tissue injury and induction of chronic intestinal inflammation has not been proposed. Even advocates of the theory that MAP causes Crohn's disease concede that infection, if present, consists of a low bacterial load and that no histochemical evidence of acid fast staining in Crohn's disease tissues is seen. This could be explained by a paucibacillary infection with an obligate intracellular, cell wall deficient bacterial form. ${ }^{19}$ In this setting, inflammation and tissue injury must be mediated by a cell mediated immune response. However, a cellular immune response to MAP has not been documented in Crohn's disease patients, ${ }^{20}$ despite increased serological responses to MAP antigens in the same patients. Another serious flaw in the MAP pathogenesis of Crohn's disease theory is the observation that these patients respond to chronic immunosuppressive therapies ${ }^{21}$ and acquired immunosuppressive infections decrease disease activity as CD4 T cell counts fall. ${ }^{22}$ In contrast, $M$ tuberculosis massively proliferates with antitumour necrosis factor or steroid treatment and $M$ avium intracellulare thrives in the intestine as CD4 counts fall in human immunodeficiency virus infected patients. It is possible that intracellular cell wall deficient MAP may not replicate well despite immunosuppression, but this issue has never been studied by in vitro investigation or in animals with Johne's disease. In the study by Autschbach et al, corticosteroid therapy was associated with lower MAP detection rates. ${ }^{12}$

The most irrefutable evidence that a microbial agent causes a disease is long term remission of clinical manifestations and an altered natural history of disease following clearance of the infection. In vitro sensitivity analyses show that clinical isolates of MAP are not responsive to traditional anti- $M$ tuberculosis agents, and therefore lack of efficacy with isoniazid, ethambutol, and rifampicin treatment for two years with a three year follow up ${ }^{23}$ does not detract from this theory. However, reports of efficacy of combinations of clarithromycin or azithromycin, rifabutin, and a variety of other agents in $58-82 \%$ of Crohn's disease patients ${ }^{10} 24$ are also not definitive due to the uncontrolled nature of these studies, the small number of patients treated, the variable treatment regimens, and the fact that these antibiotics, particularly clarithromycin, 
Table 1 Arguments for and against a Mycobacterium avium subspecies paratuberculosis (MAP) causation of Crohn's disease

Pros

(1) Clinical and pathological similarities between Johne's and Crohn's diseases ${ }^{34}$

(2) Presence in food chain (milk, meat) and water supplies ${ }^{78}$

(3) Increased detection of MAP in Crohn's disease tissues by culture, PCR, FISH ${ }^{5} 633$

(4) Positive blood cultures of MAP in Crohn's disease patients'

(5) Increased serological responses to MAP in Crohn's disease patients ${ }^{20} 34$

(6) Detection of MAP in human breast milk by culture and PCR

(7) Progression of cervical lymphadenopathy to distal ileitis in a patient with MAP infection ${ }^{35}$

(8) Therapeutic responses to combination antituberculosis therapy that include macrolide antibiotics ${ }^{1024}$

Cons

(1) Differences in clinical and pathological responses in Johne's and Crohn's diseases ${ }^{4}$

(2) Lack of epidemiological support of transmissible infection ${ }^{36}$

(3) No evidence of transmission to humans in contact with animals infected with MAP

(4) Genotypes of Crohn's disease and bovine MAP isolates not similar ${ }^{18}$

(5) Variability in detection of MAP by PCR (0-100\% in Crohn's disease and ulcerative colitis tissues) ${ }^{8}$ and serological testing ${ }^{37}$

(6) No evidence of mycobacterial cell wall by histochemical staining

(7) No worsening of Crohn's disease with immunosuppressive agents or HIV infection

(8) No documented cell mediated immune responses to MAP in patients with Crohn's disease ${ }^{20}$

(9) No therapeutic response to traditional antimycobacterial antibiotics ${ }^{23}$

MAP, Mycobacterium avium subspecies paratuberculosis; PCR, polymerase chain reaction; FISH,

fluorescent in situ hybridisation; HIV, human immunodeficiency virus.

have a broad spectrum of activity against commensal enteric bacteria. Moreover, these studies and a yet to be published ongoing controlled trial in Australia using these agents in Crohn's disease patients are flawed by not assessing IS900 DNA in biopsy specimens by PCR and serological responses to MAP before and after therapy, so that clinical results can be correlated with the presence of tissue MAP and its clearance with treatment. Selective responses in those patients with detectible MAP colonisation that clear infection with antibiotic treatment would strongly imply a causal relationship of the infection.

Our evolving molecular understanding of gene/environmental interactions offers an opportunity to reassess the MAP causation theory of Crohn's disease in a new light. NOD2/CARD15 is an intracellular receptor for muramyl dipeptide (MDP), the smallest immunologically active component of bacterial peptidoglycan. Ligation of MDP by NOD2/CARD15 activates nuclear factor $\kappa \mathrm{B}$. This pathway may contribute to clearance of intracellular bacterial infection $^{25}$ and secretion of $\alpha$ defensins by Paneth cells, which constitutively express NOD2/CARD15. ${ }^{26}$ The three most common polymorphisms of this gene are found in $25-35 \%$ of Caucasian Crohn's disease patients ${ }^{27}$ and lead to defective nuclear factor $\kappa \mathrm{B}$ activation by MDP. ${ }^{28}{ }^{29}$ Expression of the common truncation mutation of NOD2/CARD 15 is associated with defective clearance of invasive salmonella infection in epithelial cells. ${ }^{25}$ In addition, NOD2/CARD15 mutations in Crohn's disease are associated with diminished mucosal $\alpha$ defensin expression. ${ }^{30}$ Thus an attractive explanation linking NOD2/CARD15 to
Crohn's disease is that defective function of this gene results in ineffective clearance of intracellular MAP infection and in decreased luminal $\alpha$ defensin secretion that permits increased mucosal adherence and epithelial invasion of ingested organisms. Defective clearance of intracellular MAP by innate immune cells, including macrophages, could explain the seemingly paradoxical therapeutic response of some Crohn's disease patients to granulocyte-macrophage colony stimulating factor. ${ }^{31}$ However, the phenotypic information provided by Autschbach and colleagues $^{12}$ argues against an association of NOD2/CARD15 with MAP infection, as MAP was more commonly detected in colonic than ileal disease and was not more frequently found in early onset or stricturing disease. ${ }^{12}$ Likewise, patients with extensive ileocolitis responded better to macrolide antibiotics and rifabutin than did those with isolated ileal disease. ${ }^{10}$ These results directly contrast with the strong association of NOD2/ CARD15 polymorphisms with early onset ileal Crohn's disease with a stricturing phenotype. ${ }^{32}$

Crohn's disease certainly has environmental and host genetic influences that interact to cause clinically evident disease. It is equally clear that MAP is widely present in our food chain and that the DNA of this organism can be recovered from the intestine of Crohn's disease patients. Although existing data do not compellingly implicate MAP as a causal agent in Crohn's disease, neither do they definitively exclude this possibility. We must determine whether MAP infection causes human disease, which is unlikely in my opinion, or whether this environmental contaminant innocently lodges in ulcerated mucosa. Is
MAP analogous to Helicobacter pylori in peptic ulcer disease, gastritis, and gastric cancer, where host genetics and microbial virulence factors determine immune responses that mediate clinical disease in a small minority of patients exposed to a widespread infectious agent? Are we repeating the mistake of $H$ pylori where the scientific establishment resisted a new theory that challenged established paradigms of peptic ulcer disease until overwhelming clinical evidence made such resistance untenable? Well designed clinical, microbiological, and mechanistic experiments are urgently needed to definitively settle this still unresolved debate.

To establish a causal relationship between MAP and Crohn's disease, we need to determine if clearance of MAP selectively changes the natural history of disease in an infected subset of patients, perform definitive investigations of cellular immune responses to this organism in Crohn's disease and control patients, determine if NOD2/ CARD15 and other microbial signalling pathways influence intracellular MAP infection and clearance, and review results of ongoing large multi-institutional studies to detect MAP in shared coded tissues by various molecular and culture methods. These studies need to be designed and conducted by established investigators who bring no predetermined biases to this contentious topic. If MAP is responsible for a subset of Crohn's disease, public health measures must be implemented to eliminate the source of infection in our food chain and food processing practices must be modified. In addition, the medical community must develop ways to efficiently and cost effectively screen for MAP infection and develop methods to efficiently clear this organism from infected tissues, possibly through a combination of effective antibiotics and immunostimulants that enhance innate clearance responses. If there is no evidence of a causal association of MAP and Crohn's disease, we need to direct resources to other avenues of research. This controversy has persisted far too long and needs to be expeditiously resolved.

\section{Gut 2005;54:896-898.}

doi: $10.1136 /$ gut.2004.055889

Correspondence to: Dr R Balfour Sartor, UNC Department of Medicine/Division of Gastroenterology and Hepatology, CB \#7032 Room 7309 Biomolecular Bldg (MBRB), Chapel Hill, NC 27599-7032, USA; rbs@med.unc.edu Conflict of interest: None declared.

\section{REFERENCES}

1 Crohn BB, Ginzburg L, Oppenheimer GD Regional ileitis: a pathologic and clinical entity. JAMA 1932:99:1323-9. 
2 Dalzeil TK. Chronic intestinal enteritis. BMJ 1913;2:1068-9.

3 Greenstein RJ. Is Crohn's disease caused by a mycobacterium? Comparisons with leprosy, tuberculosis, and Johne's disease. Lancet Infect Dis 2003;3:507-14

4 Chiodini RJ. Crohn's disease and the mycobacterioses: a review and comparison of two disease entities. Clin Microbiol Rev 1989:2:90-117.

5 Chiodini RJ, Van Kruiningen HJ, Thayer, WR, et al. Possible role of mycobacteria in inflammatory bowel disease. I. An unclassified Mycobacterium species isolated from patients with Crohn's disease. Dig Dis Sci 1984;29:1073-9.

6 Sanderson JD, Moss MT, Tizard ML, et al Mycobacterium paratuberculosis DNA in Crohn's disease tissue. Gut 1992;33:890-6.

7 Millar D, Ford J, Sanderson J, et al. IS900 PCR to detect Mycobacterium paratuberculosis in retail supplies of whole pasteurized cows' milk in England and Wales. Appl Environ Microbiol 1996:62:3446-52

8 Mishina D, Katsel P, Brown ST, et al. On the etiology of Crohn disease. Proc Natl Acad SciUSA 1996:93:9816-20.

9 Naser SA, Schwartz D, Shafran I. Isolation of Mycobacterium avium subsp paratuberculosis from breast milk of Crohn's disease patients. Am J Gastroenterol 2000;95:1094-5.

10 Gui GP, Thomas PR, Tizard ML, et al. Two-yearoutcomes analysis of Crohn's disease treated with rifabutin and macrolide antibiotics. J Antimicrob Chemother 1997;39:393-400.

11 Naser SA, Ghobrial G, Romero C, et al. Culture of Mycobacterium avium subspecies paratuberculosis from the blood of patients with Crohn's disease. Lancet 2004;364:1039-44.

12 Autschbach F, Eisold S, Hinz U, et al. High prevalence of Mycobacterium avium subspecies paratuberculosis IS900 DNA in gut tissues from individuals with Crohn's disease. Gut 2005; 54:944-9

13 Jubb TF, Galvin JW. Effect of a test and control program for bovine Johne's disease in Victorian dairy herds 1992-2002. Aust Vet J 2004;82:228-32

14 Raizman EA, Wells SJ, Godden SM, et al. The distribution of Mycobacterium avium ssp. paratuberculosis in the environment surrounding Minnesota dairy farms. J Dairy Sci 2004;87:2959-66.
15 Grant IR. Mycobacterium paratuberculosis and milk. Acta Vet Scand 2003;44:261-6.

16 Lund BM, Gould GW, Rampling AM. Pasteurization of milk and the heat resistance of Mycobacterium avium subsp. paratuberculosis: a critical review of the data, Int J Food Microbiol 2002;77:135-45

17 Sartor RB. Microbial influences in inflammatory bowel disease: Role in pathogenesis and clinical implications. In: Sartor RB, Sandborn WJ, eds. Kirsner's inflammatory bowel diseases, 6th edn. Amsterdam: Elsevier Publishers, 2004:138-62

18 Motiwala AS, Strother M, Amonsin A, et al. Molecular epidemiology of Mycobacterium avium subsp. paratuberculosis: evidence for limited strain diversity, strain sharing, and identification of unique targets for diagnosis, J Clin Microbiol 2003;41:2015-26.

19 Chiodini RJ, Van Kruiningen HJ, Thayer WR et al. Spheroplastic phase of mycobacteria isolated from patients with Crohn's disease. J Clin Microbiol 1986;24:357-63.

20 Olsen I, Wiker HG, Johnson E, et al. Elevated antibody responses in patients with Crohn's disease against a 14-kDa secreted protein purified from Mycobacterium avium subsp. paratuberculosis. Scand J Immunol 2001;53:198-203.

21 Hanauer SB, Feagan BG, Lichtenstein GR, et al Maintenance infliximab for Crohn's disease: the ACCENT I randomised trial. Lancet 2002;359:1541-9.

22 James SP. Remission of Crohn's disease after human immunodeficiency virus infection. Gastroenterology 1988;95:1667-9.

23 Thomas GA, Swift GL, Green JT, et al. Controlled trial of antituberculous chemotherapy in Crohn's disease: a five year follow up study. Gut 1998;42:497-500.

24 Shafran I, Kugler L, el-Zaatari FA, et al. Open clinical trial of rifabutin and clarithromycin therapy in Crohn's disease. Dig Liver Dis 2002;34:22-8.

25 Hisamatsu T, Suzuki M, Reinecker HC, et al. CARD15/NOD2 functions as an anti-bacterial factor in human intestinal epithelial cells. Gastroenterology 2003;124:993-1000.

26 Lala S, Ogura Y, Osborne C, et al. Crohn's disease and the NOD2 gene: a role for paneth cells. Gastroenterology 2003;125:47-57.
27 Hugot JP, Chamaillard M, Zouali $\mathrm{H}$, et al. Association of NOD2 leucine-rich repeat variants with susceptibility to Crohn's disease. Nature 2001:411:599-603.

28 Girardin SE, Boneca IG, Viala J, et al. Nod2 is a general sensor of peptidoglycan through muramyl dipeptide (MDP) detection. J Biol Chem 2003;278:8869-72.

29 Bonen DK, Ogura Y, Nicolae DL, et al. Crohn's disease-associated NOD2 variants share a signaling defect in response to lipopolysaccharide and peptidoglycan. Gastroenterology 2003;124:140-6.

30 Wehkamp J, Harder J, Weichenthal $M$, et al NOD2 (CARD15) mutations in Crohn's disease are associated with diminished mucosal alpha-defensin expression. Gut 2004;53:1658-64.

31 Dieckgraefe BK, Korzenik JR. Treatment of active Crohn's disease with recombinant human granulocyte-macrophage colony-stimulating factor. Lancet 2002;360:1478-80.

32 Ahmad T, Tamboli CP, Jewell D, et al. Clinical relevance of advances in genetics and pharmacogenetics of IBD. Gastroenterology 2004; 126:1533-49.

33 Hulten K, El-Zimaity HM, Karttunen TJ, et al. Detection of Mycobacterium avium subspecies paratuberculosis in Crohn's diseased tissues by in situ hybridization. Am J Gastroenterol 2001;96:1529-35

34 Naser SA, Hulten K, Shafran I, et al. Specific seroreactivity of Crohn's disease patients against p35 and p36 antigens of M. avium subsp. paratuberculosis. Vet Microbiol 2000;77:497-504.

35 Hermon-Taylor J, Barnes N, Clarke C, et al. Mycobacterium paratuberculosis cervical lymphadenitis, followed five years later by terminal ileitis similar to Crohn's disease. BM 1998:316:449-53.

36 Sandler RS, Loftus EV. Epidemiology of inflammatory bowel diseases. In: Sartor RB Sandborn WJ, eds. Kirsner's inflammatory bowel diseases, 6th edn. Philadelphia: WB Saunders, 2003:245-62.

37 Bernstein CN, Blanchard JF, Rawsthorne P, et al. Population-based case control study of seroprevalence of Mycobacterium paratuberculosis in patients with Crohn's disease and ulcerative colitis. J Clin Microbiol 2004:42:1129-35.

beyond inherent basic nutrition". ${ }^{3}$ Bacteria associated with probiotic activity are most commonly lactobacilli, bifidobacteria, and streptococci but

\section{Probiotics and barrier function in colitis}

\section{P Gionchetti, K M Lammers, F Rizzello, M Campieri}

Probiotic administration may exert a protective effect in colitis by preventing mucosal barrier disruption and influencing the extent of mucosal injury

T here is strong evidence of a role for the indigenous flora in driving inflammatory responses in inflammatory bowel disease (IBD) in genetically predisposed individuals. ${ }^{1}$ For years, researchers have tried in vain to identify a specific pathogen as the cause of these chronic intestinal inflammatory disorders but the possibility that one or more bacterial agents are responsible cannot be ruled out. Considering the implications of a pathogen in IBD, as yet undiscovered due to technical limitations, it was hypothesised that modulation of an abnormal microflora in these patients by introducing high titres of "protective" bacteria might overwhelm the "aggressive" strain(s) and inhibit its deleterious effects. On this basis, probiotic treatment was proposed as a therapeutic approach. ${ }^{2}$

Probiotics are defined as "living organisms which, on ingestion in certain numbers, exert health benefits other non-pathogenic bacteria such as some strains of Escherichia coli and microorganisms such as the yeast Saccharomyces boulardii have been used in IBD.

Encouraging results have been obtained with probiotics in several experimental animal models of IBD. ${ }^{4-7}$ In humans, probiotics are effective in the prevention of pouchitis onset and relapse. ${ }^{8-10}$ Results in ulcerative colitis are promising, both in prevention of relapse and treatment of mild to moderate attacks. ${ }^{11-13}$ Results in Crohn's disease are not yet clear because of conflicting data and the limited number of well performed studies. ${ }^{14-16}$

Efforts are being made by many researchers to unravel the precise mechanisms by which probiotic bacteria and their metabolic products (short chain fatty acids, vitamins) exert their 
beneficial effects. Several mechanisms have been proposed to account for probiotic action. These include: (a) antagonistic activity against pathogenic bacteria by competing for binding sites $^{17}{ }^{18}$; (b) stimulation of mucosal defence at the level of both immune and epithelial function, by increasing sIgA production, ${ }^{19}$ decreasing proinflammatory and increasing anti-inflammatory cytokine levels, ${ }^{20-26}$ and inducing production of protective substances by the epithelium, such as antimicrobial peptides (bacteriocins) and hydrogen peroxide, mucins, ${ }^{17} 27$ and heat shock proteins, ${ }^{28}$ respectively; and (c) inhibition of bacterial translocation and reinforcement of barrier function ${ }^{2021}$ by mechanisms that have yet to be established in detail.

The paper presented in this issue of $G u t^{29}$ describes the effect of modulation of the microflora by Lactobacillus casei on disease course and extent in the trinitrobenzene sulphonic acid (TNBS) model of experimental colitis (see page 955). The elegance of this study lies in the experimental set up, which allowed controlled mucosal colonisation with indigenous flora and selected bacterial strains after removal of the native flora by antibiotics, and in the straightforward hypothesis and performance of the study; TNBS exerted a direct toxic effect on epithelial cells and disrupted the intestinal barrier, and the effect of $L$ casei on impaired barrier function and bacterial translocation in the TNBS model was examined. Colonisation of bacterial strains, measure of bacterial translocation, neutrophil tissue influx, and degree of inflammation were evaluated.

The data from this study suggest that $L$ casei administration exerts a protective effect by preventing barrier disruption by TNBS, as translocation of bacteria to mesenteric lymph nodes was significantly reduced in rats colonised with standard rat flora and $L$ casei compared with rats colonised with only standard rat flora. $L$ casei intervention influenced further extension of mucosal injury induced by TNBS, but not the nature of the colonic lesions (transmural lesions were similar in depth compared with TNBS colitis), and resulted in lower myeloid peroxidase activity, a measure of tissue neutrophil infiltration.

The exact mechanisms by which probiotics can influence barrier function remain to be elucidated. It is known that certain lactobacilli adhere to mucosal surfaces, inhibit attachment of pathogenic bacteria, and enhance secretion of mucins. ${ }^{17} 1827$ These properties may be instrumental in improving mucosal barrier function and decreasing permeability to macromolecules and toxins. Recently it has been shown that a mixture of probiotic bacteria, in addition to decreasing proinflammatory cytokines-which increase intestinal permeability (interferon $\gamma$ ) and induce a cascade of inflammatory events (interleukin (IL) - $1 \beta$, tumour necrosis factor $\alpha$, IL-8) resulting in mucosal injury by invading immune cells (neutrophils, tissue macrophages, dendritic cells ${ }^{20-26}$ reinforce barrier function by secretion of soluble factors that enhance barrier integrity and by regulation of tight junctions (TJ). ${ }^{2021}$ TJ are dynamic structures which represent the major barrier within the paracellular pathway and regulate in a rapid and coordinated way paracellular permeability. Many pathogenic bacteria modulate intestinal permeability by alteration of $\mathrm{TJ}^{30}$ Probiotics prevent Salmonella induced alteration of the distribution of the TJ protein zonula occludens 1 and Salmonella induced enhanced permeability by increasing transepithelial resistance and decreasing mannitol flux. ${ }^{20}{ }^{21}$

Maintenance of epithelial barrier function is essential for the preservation of mucosal integrity. Altered TJ structure in ulcerative colitis results in impaired barrier function. ${ }^{31}$ Increased permeability in IBD is observed during the active phase of the disease and therefore reinforcement of barrier function, together with their immune modulatory and metabolic properties, may be central in the mechanism of action of probiotic bacteria. Further investigations on how probiotics regulate the TJ complex and influence intestinal permeability are warranted.

Gut 2005:54:898-900.

doi: $10.1136 /$ gut.2004.060640

\section{Authors' affiliations}

P Gionchetti, K M Lammers, F Rizzello, M Campieri, Policlinic S Orsola, University of Bologna, Department of Internal Medicine and Gastroenterology, Bologna, Italy

Correspondence to: Dr P Gionchetti, Policlinic Sant'Orsola, Department of Internal Medicine and Gastroenterology, University of Bologna, Via Massarenti 9, 40138 Bologna, Italy; paolo@med.unibo.it

Conflict of interest: None declared.

\section{REFERENCES}

1 Guarner F, Casellas F, Borruel N, et al. Role of microecology in chronic inflammatory bowel diseases. Eur J Clin Nutr 2002;56:S34-8.

2 Campieri M, Gionchetti P. Probiotics in inflammatory bowel disease: new insight to pathogenesis or a possible therapeutic alternative? Gastroenterology 1999:116:1246-9.

3 Schaafsma G. State of the art concerning probiotic strains in milk products. IDF Nutr NewsI 1996:5:23-4.
4 Fabia R, Ar'rajab A, Johansson M-L, et al. The effect of exogenous administration of Lactobacillus reuterii R2LC and oat fiber on acetic acid-induced colitis in the rat. Scand J Gastroenterol 1993;28:155-62.

5 Madsen KL, Tavernini MM, Doyle JSG, et al. Lactobacillus sp prevents development of enterocolitis in interleukin-10 gene-deficient mice. Gastroenterology 1999;116:1107-14.

6 Schultz M, Veltkamp C, Dieleman LA, et al. Lactobacillus plantarum $299 \mathrm{~V}$ in the treatment and prevention of spontaneous colitis in interleukin-10 deficient mice. Inflamm Bowel Dis 2002;8:71-80

7 Shibolet O, Karmeli F, Eliakim R, et al. Variable response to probiotics in two models of experimental colitis in rats. Inflamm Bowel Dis 2002;8:399-408.

8 Gionchetti P, Rizzello F, Venturi A, et al. Oral bacteriotherapy as maintenance treatment in patients with chronic pouchitis: a double-blind, placebo-controlled trial. Gastroenterology 2000;1 19:305-9.

9 Mimura T, Rizzello F, Helwig U, et al. Once daily high dose probiotic therapy for maintaining remission in recurrent or refractory pouchitis. Gut 2004;53:108-14.

10 Gionchetti P, Rizzello F, Venturi A, et al. Prophylaxis of pouchitis onset with probiotic therapy: a double blind, placebo controlled trial. Gastroenterology 2003; 124:1202-9.

11 Kruis W, Fric P, Pokrotnieks J, et al. Maintaining remission of ulcerative colitis with Escherichia Coli Nissle 1917 is as effective as with standard mesalazine. Gut 2004;53:1617-23.

12 Venturi A, Gionchetti P, Rizzello F, et al. Impact on the faecal flora composition of a new probiotic preparation. Preliminary data on maintenance treatment of patients with ulcerative colitis (UC) intolerant or allergic to 5-aminosalicylic acid (5 ASA). Aliment Pharmacol Ther 1999;13:1103-8.

13 Fedorak RN, Gionchetti P, Campieri M, et al. VSL\#3 probiotic misture induces remission in patients with active ulcerative colitis. Gastroenterology 2003; 124:A377

14 Guslandi M, Mezzi G, Sorghi M, et al. Saccharomyces boulardii in maintenance treatment of Crohn's disease. Dig Dis Sci 2000;45: 1462-4.

15 Prantera C, Scribano ML, Falasco G, et al. Ineffectiveness of probiotics in preventing recurrence after curative resection for Crohn's disease: a randomised contraolled trial with Lactobacillus GG. Gut, 2002;51;405-9.

16 Campieri M, Rizzello F, Venturi A, et al. Combination of antibiotic and probiotic treatment is efficacious in prophylaxis of post-operative recurrence of Crohn's disease: a randomised controlled study vs mesalazine. Gastroenterology 2000;118:A781.

17 Mack DR, Michail S, Wei S, et al. Probiotics inhibit enteropathogenic $\mathrm{E}$. coli adeherence in vitro by inducing intestinal mucin gene expression. Am J Physiol 1999;276:G941-50.

18 Bernet MF, Brassart D, Neeser JR, et al. Lactobacillus acidophilus LA1 binds to cultured human intestinal cell lines and inhibits cell attachment and cell invasion by enterovirulent bacteria. Gut 1994;35:483-9.

19 Gewirtz AT, Liu Y, Sitaraman SV, et al. Intestinal epithelial pathobiology: past, present and future. Best Pract Res Clin Gastroenterol 2002; 16:851-67.

20 Madsen K, Cornish A, Soper P, et al. Probiotic bacteria enhance murine and human intestinal epithelial barrier function. Gastroenterology 2001;121:580-91.

21 Otte J-M, Podolsky DK. Functional modulation of enterocytes by gram-positive and gram-negative microorganisms. Am J Physiol Gastrointest Liver Physiol 2004;286:G613-26.

22 Lammers KM, Helwig U, Swennen E, et al. Effect of probiotic strains on interleukin 8 production by HT29/19A cells. Am J Gastroentero 2002;97: $1182-6$.

23 Ulisse S, Gionchetti P, D'Alo S, et al. Expression of cytokines, inducible nitric oxide synthase, and matrix metalloproteinases in pouchitis: effects of probiotic treatment. Am J Gastroenterol 2001;96:2691-9. 
24 Jijon $\mathrm{H}$, Backer J, Diaz $\mathrm{H}$, et al. DNA from probiotic bacteria modulates murine and human epithelial and immune function. Gastroenterology 2004; 126:1358-73.

25 Hart AL, Lammers KM, Brigidi P, et al. Modulation of human dendritic cell phenotype and function by probiotic bacteria. Gut 2004;53:1602-9.

26 Lammers KM, Brigidi P, Vitali B, et al. Immunomodulatory effects of probiotic bacteria DNA: IL-1 and IL-10 response in human peripheral blood mononuclear cells. FEMS Immunol Med Microbiol 2003;38:165-72.
27 Willemsen LE, Koetsier MA, van Deventer SJ, et al. Short chain fatty acidsstimulate epithelial mucin 2 expression through differential effects on prostaglandin $E(1)$ and $E(2)$ production by intestinal myofibroblasts. Gut 2003;52:1442-7.

28 Petrof EO, Kojima K, Ropeleski MJ, et al. Probiotics inhibit nuclear factor-kappaB and induce heat shock proteins in colonic epithelial cells through proteasome inhibition. Gastroenterology 2004; 127:1474-87.

29 Llopis M, Antolín M, Guarner F, et al. Mucosa colonisation with Lactobacillus casei mitigates barrier injury induced by exposure to trinitronbenzene sulphonic acid. Gut 2005;54:955-9.

30 Fasano A, Nataro JP. Intestinal epithelial tight junctions as targets for enteric bacteriaderived toxins. Adv Drug Deliv Rev 2004:56:795-807.

31 Schmitz H, Barmeyer C, Fromm H, et al. Altered tight junction structure contributes to the impaired epithelial barrier function in ulcerative colitis. Gastroenterology 1999;116:301-9.

\title{
Reinforcing the mucus: a new therapeutic approach for ulcerative colitis?
}

\author{
P R Gibson, J G Muir
}

Luminal delivery of phosphatidyl rich phospholipids appears to reduce mucosal inflammatory activity in a high proportion of patients with chronically active ulcerative colitis. The simplicity and apparent safety of this therapeutic approach offers new insights into the importance of the mucus barrier in the pathogenesis and treatment of ulcerative colitis

T he treatment of active mucosal inflammation in ulcerative colitis remains challenging. Current therapies have limited efficacy and may be associated with clinically significant adverse effects. There is room for new therapeutic approaches. While nearly all of our current pharmacological approaches involve attacking various immune and inflammatory pathways in order to facilitate healing, few in the clinician's current arsenal are directed towards enhancing or protecting the colonic epithelial barrier. Is this situation about to change?

The understanding of the pathogenesis of ulcerative colitis has not considerably progressed over the last decade. The proponents of concepts that the primary abnormalities lie within immune and inflammatory mechanisms have stumbled in attempts to explain the striking features of ulcerative colitis, such as the diffuse nature of the inflammation, its confinement to the mucosal compartment, and its distribution in the large bowel. The alternative concept that primary abnormalities lie within an abnormal epithelial barrier sits more comfortably with these characteristic features of the disease. ${ }^{1}$ The barrier has regional differences in structure, composition, and function, which offer simple explanations for, for example, disease distribution. The nature of the inflammatory response in ulcerative colitis-intense polymorph infiltration and predominant antibody mediated $\left(\mathrm{T}_{\mathrm{H}} 2\right)$ responses with less prominent $\mathrm{T}$ cell activation-is most consistent with exposure of the immune system to large numbers of different "foreign" molecules. ${ }^{2}$ Such events might be anticipated in a situation where multiple molecules are able to pass through a deficient epithelial barrier. This is in marked contrast with the situation in Crohn's disease where the patchy inflammation involving deeper layers of the intestinal wall and draining lymph nodes, together with dominant $\mathrm{T}$ cell activation and $\mathrm{T}_{\mathrm{H}} \mathrm{l}$-type cytokine profile that characterises the response to a limited number of antigens specifically taken up and presented to $\mathrm{T}$ cells via follicle associated epithelial cells. ${ }^{23}$

Studies that date back more than 20 years have demonstrated that the colonic epithelium is abnormal in structure and function in patients with ulcerative colitis. The epithelium comprises cells that are metabolically abnormal (such as deficient $\beta$-oxidation ${ }^{4}$ or sulphation of phenols ${ }^{5}$ ), respond abnormally to stress (as shown by the response in vitro after its separation from the basement membrane ${ }^{67}$ ), and have an abnormal cell membrane (such as abnormal permeability ${ }^{8}$. The mucus layer is abnormal, both in its thickness ${ }^{9}$ and composition (such as abnormal glycosylation of mucins ${ }^{10-12}$ and abnormalities of the phospholipid component $\left.{ }^{13}\right)$. Many of these abnormalities are independent of the presence of mucosal inflammation, although whether they are primary abnormalities or secondary to other processes has never been definitively demonstrated. Why such abnormalities are presentwhether autoimmune injury to the epithelium is occurring, whether there might be a genetic basis for epithelial structure or function, whether there are luminal factors that might induce abnormal behaviour of the epithelium, or a combination of any or all of thesehas been the basis of much study and speculation without definitive answers.

Targeting the epithelial barrier in order to reduce the stimulus to inflammatory events, to enhance healing of actively inflamed mucosa, and to prevent relapse have also been the subject of much speculation and study. Approaches have ranged from improving the regenerative ability of the epithelium (such as the use of growth factors ${ }^{14}{ }^{15}$ ), to trying to enhance energy substrate supply (using butyrate enemas $^{16}$ ), and to enhancing the mucous barrier (with trefoil peptides ${ }^{15} 17$ or inhibition of bacterial sulphatases with bismuth $^{18}$ ). None of these approaches has yet to be promoted from potential therapy to use in regular practice because, for example, the theoretical basis was misguided, efficacy was limited, or further development was hindered by funding difficulties and commercial realities. Will further attention to colonic mucus change this situation?

\section{COLONIC MUCUS}

The normal colon is lined by a layer of mucus that is more than $100 \mu$ m thick. ${ }^{9}$ The mucus serves essential functions. It is a lubricant ensuring low friction between moving structures (luminal contents) and the epithelium. This conceptually simple but essential protective function is predominantly the responsibility of surface acting phospholipids. ${ }^{19}$ 
They form an oligolamellar lining that converts the hydrophilic epithelial surface into a hydrophobic one that interfaces with luminal contents. The tight packing together of fatty acid chains provides a good basis for a hydrophobic barrier. Indeed, the regions of the gastrointestinal tract with the most developed hydrophobicity are the stomach and colon, where the potential for injurious insults from luminal factors are the greatest. ${ }^{20}$ Most attention in recent years has been paid to other mucous components that subserve complementary protective functions. Mucins are glycoproteins that function to exclude large molecules (polymers with a molecular weight $>20000$ ) that are not glycoproteins, and to trap other molecules either non-specifically via general "stickiness" or more specifically via carbohydrate structures (lectin binding sites) that may be similar to those on the cell surface. ${ }^{21}$ Such trapped matter can be discarded by the constant removal of mucus. It is no surprise then that mucus secretion is increased in the face of threats and this may be mediated, at least in part, by immune events. ${ }^{22}$ The mucus environment also supports the presence of other protective proteins and peptides such as secretory IgA, ${ }^{23}$ lactoferrin, ${ }^{24}$ and trefoil peptides..$^{25}$

Of all of these components, it has not been clear what is or are the most important from functional, pathogenic, or treatment points of view. Much of the glamour and excitement have surrounded the mucin glycoproteins and other secreted proteins within the mucus. However, recent evidence suggests that the phospholipid component might be a critical factor that can be readily modulated when the mucous barrier is failing.

\section{PHOSPHOLIPIDS}

Phospholipids, the major lipid components of mucus, are amphiphilic molecules and contain a polar head group and non-polar hydrocarbon (fatty acid) tails. The major classes of phospholipids include phosphatidylcholine (PC), phosphatidylethanolamine, phosphatidylinostiol, and phosphatidylserine. In colonic mucus, PC and lysophosphatidylcholine (LPC) are the major species. ${ }^{13}$ LPC is an intermediate in the metabolism of PC but is also produced after the hydrolysis of PC by phospholipase A2. ${ }^{26}$ Orientation of the lipophilic region of the phospholipid and the nature of the fatty acids characterise the hydrophobicity of the mucus gel layer. ${ }^{20}$ The fatty acid tails extend into the lumen to form a "non-wettable" resistant layer. ${ }^{2027}$ They also extend from the mucosal cell side of the mucus gel. ${ }^{27}$ In mucus, the PC species typically contain one saturated (palmitic acid 16:0 or stearic acid 18:0) and one unsaturated (oleic acid 18:1or linoleic acid 18:2) fatty acid with PC (that is, PC 16:0/18:1 and PC 18:0/18:2). ${ }^{13}$ This contrasts with the PC of pulmonary surfactant, dipalmitoylphosphatidylcholine, which contains two saturated fatty acids, palmitic acid (PC 16:0/16:0). ${ }^{19}$

The origin of PC in mucus has not been established and more research is required to understand how, when, and where these surface active phospholipids are synthesised, stored, and secreted. In animal studies, there is some evidence that $\mathrm{PC}$ is primarily secreted by the jejunum and ileum, suggesting that PC is delivered to the mucus via the lumen. ${ }^{13}$ In these studies, the contribution of PC produced via the colonic epithelium appeared to be minimal. It seems somewhat surprising and highly unlikely that a local source of PC secretion into the mucosal gel layer is not operational. Goblet cells are an obvious site for further investigation. Approaches that have been used to understand the role of surface active phospholipids in the gastric mucosa and as pulmonary surfactant could be readily employed to gain a greater understanding about the production of mucous PC in the colon. A great deal has been learnt by the use of special probes and stains specific for lipophilic areas and choline based phospholipids (see Lichtenberger ${ }^{20}$ ), and their application to colonic mucus seems warranted.

\section{MUCUS PHOSPHOLIPIDS IN ULCERATIVE COLITIS}

As outlined above, mucus is abnormal in patients with ulcerative colitis. There is, however, limited knowledge regarding the phospholipid component of colonic mucus in ulcerative colitis. Recently, quantitatively less PC and LPC were reported in samples taken from the rectal mucosa of patients with ulcerative colitis than from healthy controls and patients with Crohn's disease. $^{13}$ This could be due to reduced production, increased breakdown, or both.

If indeed goblet cells do contribute to the PC content of colonic mucus, they might play more than a passive role in PC depletion of mucus. Goblet cell depletion is a more prominent pathological feature of ulcerative colitis than for Crohn's colitis. While it might just reflect excessive stimulation of the goblet cells to discharge their mucus, the cells might also be defective in their ability to incorporate PC into the mucus, offering another candidate for the primary abnormality in ulcerative colitis.

Control of PC biosynthesis is a key in the apoptotic programme so that agents that induce apoptosis turn off the biosynthesis of PC. ${ }^{28}$ Most epithelial cell death in ulcerative colitis appears to follow an apoptotic pathway..$^{29}$ Thus the increased apoptosis that is occurring in the epithelium may deplete the pool of PC by inhibiting its biosynthesis.

PC can be destroyed within the epithelium, thereby depleting the pool of PC available for secretion into mucus, or can be destroyed within the mucus itself. Mucosal phospholipase A2 activity is increased in patients with ulcerative colitis or Crohn's disease $e^{31} 32$ and this activity resides in the epithelium. ${ }^{33}$ Protein kinase $\mathrm{C}$, which is involved in several signal transduction pathways linked with inflammatory responses (see Brown and colleagues ${ }^{34}$ ), activates a PC specific phospholipase $\mathrm{C}$ in the plasma membrane with subsequent breakdown of PC. ${ }^{35}$ Indeed, colonic mucosa from patients with ulcerative colitis has significantly elevated activity of protein kinase $\mathrm{C}$ in the particulate fraction compared with that in normal mucosal samples. ${ }^{36}$ Insertion of fluorescent analogues of PC into the plasma membrane of cells followed by activation of protein kinase $\mathrm{C}$ with phorbol esters has been used to follow the movement of PC and its metabolites via fluorescent microscopy. ${ }^{37}$ A similar approach could be used to gain a greater understanding about the fate of PC in the colonic mucus in ulcerative colitis and in healthy individuals.

Once phospholipids enter the mucus they remain vulnerable to the action of phospholipases, which may be of epithelial origin or derive from mucosa associated bacteria. In the stomach, Helicobacter pylori colonises the mucous layer in part by producing phospholipases A1, A2, and C, and can extract the host phospholipids for its own protective coating..$^{20} \mathrm{H}$ pylori can also generate high concentrations of ammonium ion that competes with phospholipids for negatively charged glycoprotein binding sites. ${ }^{20}$ It is intriguing to speculate about the possible role of a $H$ pylori-like bacterium that might be responsible (in part at least) for the breakdown of the colonic mucous barrier in ulcerative colitis. Large numbers of bacteria are found within the depleted mucous layer of these patients, ${ }^{38} 39$ but whether such bacteria are efficient producers of phospholipases is not known.

The net result of reduced biosynthesis and increased breakdown of phospholipids within the mucosa might be a PC starved system in ulcerative colitis with subsequent depletion of PC available for mucus. Indeed, the observation that plasma phospholipid levels are low in patients with severe ulcerative colitis 
supports such a concept. ${ }^{40}$ If this situation were combined with excessive destruction of PC within the mucus layer itself, the ability of PC to offer adequate barrier and lubricant function might be severely compromised. Could correction of phospholipid deficiency of the mucosa and/or mucus be of therapeutic value in ulcerative colitis?

\section{PHOSPHOLIPIDS AS A THERAPY}

Phospholipids are readily taken up by mucus, so that the mucous content can be substantially increased by their topical administration. In experimental animals, where there is no abnormality of mucus, topical PC protects the mucosa from luminal insults in the form of acetic acid and trinitrobenzenesulphonic acid, which usually induce colitis. ${ }^{41}{ }^{42}$ It might be anticipated that the protective and lubricant function of mucus would be considerably enhanced by topical application of PC in a situation such as ulcerative colitis where PC content is reduced. ${ }^{13}$ Such a simple concept has recently been evaluated ${ }^{43}$ and the results of a randomised controlled trial are reported in this issue of Gut (see page 966). Delivery to the large bowel lumen was achieved by coating of PC enriched phospholipids with Eudragit-s 100. Release of phospholipids from this $\mathrm{pH}$ dependent coating would be expected to predominantly occur in the terminal ileum and proximal colon, a situation mimicking the putative main source of phospholipids in the colonic mucus. Details of the origin (for example, from soy or egg), and the type of phospholipids and fatty acid species used in this study were not described. Nevertheless, PC was successfully incorporated into rectal mucus confirming that the delivery system works.

In a population of 60 patients with chronically active disease, the efficacy of the PC was astoundingly good over a three month treatment period. Compared with a response of $10 \%$ in the placebo arm, $90 \%$ of the phospholipid treated group responded and 53\% were in remission after three months of therapy. No clinically significant side effects were noted. Is this too good to be true?

There were problems with the study design. Despite being described as a single centre study, end points were scored in multiple centres for practical reasons. However, as blinding and randomisation seemed appropriate, heterogeneity of assessment is unlikely to be a significant factor in skewing the results. There were also no data on the time course of efficacy, although a comment in the discussion indicated a slow onset of effect over weeks. The dearth of adverse events in a three month study is somewhat surprising to those used to dealing with randomised controlled drug trials. This suggests laxity in documenting every minor event but again does not detract from the efficacy demonstrated. The placebo treated patients faired badly. A $10 \%$ response (and remission) rate is at the lower end of what might be anticipated in most trials, except that patients with chronically active disease, as selected, might have a lower placebo response. The choice of placebo, Eudragit-S 100 coated cellulose, may not have been appropriate. Cellulose would be delivered to the colonic lumen in an identical fashion to that of the phospholipids and, since it is not fermented by colonic bacteria, it might be considered benign and inert. However, cellulose might potentially be abrasive to the mucosa, this being a postulated mechanism by which nonfermentable fibre stimulates epithelial proliferation in fibre starved atrophic colon in otherwise healthy rats. ${ }^{44}$ The placebo therefore might have worsened the outcome. On the other hand, there is no evidence that non-fermented fibre is detrimental to the course of ulcerative colitis. Whatever the case, it is still reasonable to say that three months of therapy with PC rich phospholipids delivered to the colonic lumen were convincingly efficacious in inducing remission in patients with chronically active ulcerative colitis.

What about the mechanism of action? It would be precarious to assign this efficacy to the improved hydrophobicity and barrier function of the mucus without confirmatory data. The hydrophobicity of the mucosal layer can be quantified from the "contact angle" after a drop of saline is placed on the mucosal surface. ${ }^{27}$ Whether this simple test can be carried out on biopsy specimens or even at colonoscopy is uncertain, but such an assessment in patients with ulcerative colitis seems worthwhile. Alternatively, effects on mucus might only be a minor player in the efficacy. Replenishment of the epithelial pool of PC, with its potential positive effects on improving epithelial health, limiting epithelial destruction, and suppressing its involvement with inflammatory mechanisms, as discussed above, might also be an important mechanism of action.

\section{FUTURE DIRECTIONS}

The findings that treatment with PC rich phospholipids permits healing of otherwise difficult to treat ulcerative colitis opens a new approach to the treatment of ulcerative colitis. There is the important need to confirm the results using a more appropriate placebo (perhaps free unsaturated fatty acid such as linoleic acid in place of the cellulose), to determine the appropriate dose, and to define the time course of effect. Additional questions are raised by the complex nature of the phospholipid mixture used. For example, is the effect observed indeed due to the PC component or is the active moiety a minor part of the phospholipid mixture, such as the unsaturated fatty acid component? The question of how this phospholipid mixture is achieving its efficacy, particularly whether it is acting via reinforcement of the mucus, as seems logical, or by other mechanisms, needs to be addressed.

While there has been much previous focus on the mucin glycoproteins, this work shows that more attention needs to be drawn to the less glamorous lipid component, which is not simply playing an inert structural role in the mucus gel layer but rather is a dynamic component of a complex barrier system. The putative efficacy of PC might be enhanced by better distribution using spreading agents. Perhaps liposomes of PC could be used to introduce other therapies such as anti-inflammatory drugs or even antisense RNA that will assist with epithelial healing-two for the price of one! There is also the potential to introduce phospholipids and fatty acid species, such as arachidonic and butyric acids that may have cytoprotective properties. Welcome phospholipids to the cutting edge of ulcerative colitis!

Gut 2005;54:900-903.

doi: $10.1136 /$ gut.2004.058453

\section{Authors' affiliations}

P R Gibson, J G Muir, Monash University Department of Medicine and Department of Gastroenterology, Box Hill Hospital, Box Hill, Victoria, Australia

Correspondence to: Professor P Gibson, Department of Gastroenterology, Box Hill Hospital, Box Hill, Victoria 3128, Australia; Peter.Gibson@med.monash.edu.au

Conflict of interest: None declared.

\section{REFERENCES}

1 Gibson PR. Ulcerative colitis - an epithelial disease? Ballieres Clin Gastroenterol 1997; 1:17-33.

2 Pallone F, Monteleone G, Monteleone I, et al. The immune system in inflammatory bowel disease. In: Satsangi L, Sutherland LR, eds. Inflammatory bowel diseases. Edinburgh: Churchill Livingstone, 2003:85-93.

3 Pavli P, Gibson PR. Pathogenic factors in inflammatory bowel disease. II. Crohn's disease. Dig Dis 1992;10:72-86.

4 Roediger WEW. The colonic epithelium in ulcerative colitis - an energy deficiency disease? Lancet 1980;2:712-15.

5 Ramakrishna BS, Roberts-Thompson JC, Pannall PR, et al. Impaired sulphation of phenol by the colonic mucosa in quiescent and active ulcerative colitis. Gut 1991;32:46-9.

6 Gibson PR, Rosella O. Interleukin-8 secretion by colonic crypt cells in vitro: a response to injury that is suppressed by butyrate and enhanced in 
inflammatory bowel disease. Gut 1995; 37:536-43.

7 Gibson PR, Rosella O. Abnormalities of the urokinase system in colonic crypt cells from patients with ulcerative colitis. Inflamm Bowel Dis 1996:2:105-14.

8 Gibson P, Rosella R, Nov R, et al. Colonic epithelium is diffusely abnormal in ulcerative colitis and colorectal carcinoma. Gut 1995:36:857-63.

9 Pullan RD, Thomas GA, Rhodes $M$, et al. Thickness of adherent mucus gel on colonic mucosa in humans and its relevance to colitis. Gut 1994;35:353-9.

10 Rhodes JM, Black RR, Gallimore R, et al Histochemical demonstration of desialation and desulphation of normal and inflammatory bowel disease rectal mucus by faecal extracts. Gut 1985;26:1312-18.

11 Raouf AH, Tsai HH, Parker N, et al. Sulphation of colonic and rectal mucin in inflammatory bowel disease: reduced sulphation of rectal mucus in ulcerative colitis. Clin Sci 1992:83:623-6.

12 Morita H, Kettlewell MG, Jewell DP, et al. Glycosylation and sulphation of colonic mucus glycoproteins in patients with ulcerative colitis and in healthy subjects. Gut 1993;34:926-32.

13 Ehehalt R, Wagenblast J, Erben G, et al Phosphatidylcholine and lysophosphatidylcholine in intestinal mucus of ulcerative colitis patients. A quantitative approach by nanoelectrospray tandem mass spectrometry. Scand J Gastroenterol 2004;39:737-42

14 Howarth GS, Xian CJ, Read LC. Insulin-like growth factor-I partially attenuates colonic damage in rats with experimental colitis induced by oral dextran sulphate sodium. Scand J Gastroenterol 1998;33:180-90.

15 FitzGerald AJ, Pu M, Marchbank T et al. Synergistic effects of systemic trefoil factor family 1 (TFF1) peptide and epidermal growth factor in a rat model of colitis. Peptides 2004;25:793-801.

16 Scheppach W. Treatment of distal ulcerative colitis with short-chain fatty acid enemas. A placebo-controlled trial. German-Austrian SCFA Study Group. Dig Dis Sci 1996;41:2254-9.

17 Vandenbroucke K, Hans W, Van Huysse J, et al Active delivery of trefoil factors by genetically modified Lactococcus lactis prevents and heals acute colitis in mice. Gastroenterology 2004; 127:502-13.
18 Tsai HH, Dwarakanath AD, Hart CA, et al. Increased faecal mucin sulphatase activity in ulcerative colitis: a potential target for treatment. Gut 1995;36:570-6

19 Hills BA. Surface-acting phospholipid: a Pandora's box of clinical applications. Part II. Barrier and lubricating properties. Int Med J 2002;32:242-51

20 Lichtenberger LM. The hydrophobic barrier properties of gastrointestinal mucus. Annu Rev Physiol 1995:57:565-83.

21 Clamp J. The role of mucus in human intestinal defence. In: Losowsky MS, Heatley RV, eds. Gut defences in clinical practice. Edinburgh: Churchill Livingstone, 1986:83-94.

22 Lake AM Bloch KJ, Neutra MR, et al. Intestinal goblet cell mucus release. II. In vivo stimulation by antigen in the immunized rat. $J$ Immunol 1979;122:834-7.

23 Brandtzaeg P. Molecular and cellular aspects of the secretory immunoglobulin system. APMIS 1995:103:1-19.

24 Weinberg, ed. Human lactoferrin: a novel therapeutic with broad spectrum potential. J Pharm Pharmacol 2001;53:1303-10.

25 Sands BE, Podolsky DK. The trefoil peptide family. Annu Rev Physiol 1996;58:253-73.

26 Prokazova NV, Zvezdina ND, Korotaeva AA. Effect of lysophosphatidylcholine on transmembrane signal transduction. Biochemistry 1998;63:31-7.

27 Hills BA. Surface-acting phospholipid: a Pandora's box of clinical applications. Part I. The lung and air spaces. Int Med J 2002;32:170-8.

28 Wright MM, Howe AG, Zaremberg V. Cell membranes and apoptosis: role of cardiolipin, phosphatidylcholine, and anticancer lipid analogues. Biochem Cell Biol 2004;82:18-28.

29 Iwamoto M, Koii T, Makiyama K, et al. Apoptosis of crypt epithelial cells in ulcerative colitis. J Pathol 1996; 180:152-9.

30 Kruidenier L, Kuiper I, Lamers CB, et al. Intestinal oxidative damage in inflammatory bowel disease: semi-quantification, localization, and association with mucosal antioxidants. J Pathol 2003;201:28-36.

31 Minami T, Tojo H, Shinomura $Y$, et al. Increased group II phospholipase A2 in colonic mucosa of patients with Crohn's disease and ulcerative colitis. Gut 1994;35:1593-9.

32 Morita H, Nakanishi K, Dohi T, et al. Phospholipid turnover in the inflamed intestinal mucosa: arachidonic acid-rich phosphatidyl/ plasmenyl-ethanolamine in the mucosa in inflammatory bowel disease. J Gastroenterol 1999;34:46-53

33 Minami T, Shinomura Y, Miyagawa J, et al. Immunohistochemical localization of group II phospholipase A2 in colonic mucosa of patients with inflammatory bowel disease.

Am J Gastroenterol 1997;92:289-92.

34 Brown JF, Chang Q, Soper BD, et al. Protein

kinase $\mathrm{C}$ mediates experimental colitis in the rat. Am J Physiol 1999:276:G583-90.

35 Nishizuka Y. Intracellular signaling by hydrolysis of phospholipids and activation of protein kinase C. Science 1992;258:607-14.

36 Sakanove $Y$, Hatada $T$, Horai $T$, et al. Protein kinase $\mathrm{C}$ activity of colonic mucosa in ulcerative colitis. Scand J Gastroenterol 1992;27:275-80.

37 Glatz JA, Muir JG, Murray AW. Direct evidence for phorbol ester-stimulated accumulation of diacylglycerol derived from phosphatidylcholine. Carcinogenesis 1987;8:1943-5

38 Schultsz C, Van Den Berg FM, Ten Kate FW, et al. The intestinal mucus layer from patients with inflammatory bowel disease harbors high numbers of bacteria compared with controls. Gastroenterology 1999;117:1089-97.

39 Kleessen B, Kroesen AJ, Buhr HJ, et al. Mucosal and invading bacteria in patients with inflammatory bowel disease compared with controls. Scand J Gastroenterol 2002;37:1034-41

40 Gjone E. Plasma phospholipids in ulcerative colitis. A quantitative thin layer chromatographic study. Scand J Clin Lab Invest 1966;18:263-7.

41 Fabia R, Ar'Rajab A, Willen R, et al. Effects of phosphatidylcholine and phosphatidylinositol on acetic-acid-induced colitis in the rat. Digestion 1992:53:35-44

42 Mourelle M, Guarner F, Malagelada JR. Polyunsaturated phosphatidylcholine prevents stricture formation in a rat model of colitis. Gastroenterology 1996;110:1093-7.

43 Stremmel W, Merle U, Zahn A, et al. Retarded release phsophatidylcholine benefits patients with chronic active ulcerative colitis. Gut 2005;54:966-71.

44 Mariadason JM Catto-Smith A, Gibson PR Modulation of distal colonic epithelial barrier function by dietary fibre in normal rats. Gut 1999;44:394-9

\section{Insulin resistance and steatosis in hepatitis $C$ virus infection}

\section{A Zekry, J G McHutchison, A M Diehl}

The relationship between hepatitis $\mathrm{C}$ virus (HCV), steatosis, and insulin resistance is genotype specific, and steatosis and insulin resistance are closely linked to the progression of liver disease in $\mathrm{HCV}$ infected patients

0 ince the identification of hepatitis $C$ virus (HCV) in the late 1980s chronic HCV infection has emerged as a complex multifaceted disease with manifestations extending beyond the liver. As such, hepatic steatosis, insulin resistance (IR), and type II diabetes have been observed to occur more frequently in association with HCV

infection than other chronic inflammatory liver disease. ${ }^{1}$ A proportion of $\mathrm{HCV}$ infected patients with steatosis also exhibit several of the clinical features seen in non-alcoholic steatohepatitis (NASH), questioning the significance of these metabolic disorders in the pathogenesis of HCV related liver disease. Hence, considerable HCV research has recently been directed towards understanding the mechanisms underlying the development of these metabolic manifestations in HCV infected patients and their implications in the progression of liver disease. Several important questions have been examined: are these metabolic disorders in HCV infected patients a result of viral or host factors and, if viral, how do viral proteins interfere with lipid and insulin metabolism? What is the primary event in these patients (steatosis or IR) and what are the implications of steatosis and IR in the pathogenesis of liver disease? Finally, how can we exploit our current knowledge for developing effective therapeutic strategies for HCV infected patients?

In this issue of Gut, Fartoux and colleagues $^{2}$ utilise the homeostasis model assessment for IR (HOMA IR) index to study the association between steatosis and IR in patients with chronic HCV infection (see page 1003). In order to examine this association, the authors excluded patients with alternate factors 
Table 1 Clinical evidence for a steatogenic effect for genotype 3

- Hepatic steatosis is present in the majority of patients with genotype 3 infection

- Hepatic steatosis correlates with the level of HCV RNA in serum and the liver

- In patients infected with genotype 3 (but not genotype 1), successful viral clearance with antiviral therapy results in the disappearance of steatosis, only to recur on viral relapse

- IR has been observed to be less common among genotype 3 infected patients, even in those with extensive hepatic steatosis

$\mathrm{HCV}$, hepatitis $C$ virus; $\mathbb{R}$, insulin resistance.

known to be associated with the development of steatosis (such as alcohol intake $>20 \mathrm{~g} /$ day or diabetes). Their findings confirm earlier observations ${ }^{3-5}$ that differing and genotype specific mechanisms characterise the development of hepatic steatosis in HCV infected patients. Accordingly, steatosis in genotype 3 infected patients is primarily viral mediated (cytopathic) whereas host factors, principally those associated with IR and its clinical attributes, are responsible for the development of steatosis in the genotype 1 infected patient.

\section{DIRECT STEATOGENIC EFFECT OF HCV}

Evidence for a HCV genotype 3 specific steatogenic effect has come from several clinical observations (table 1$).^{36-8}$ Furthermore, this direct steatogenic effect of HCV is highly reproducible in transgenic mice and cell culture models of hepatitis $\mathrm{C}$, in which overexpression of viral protein (such as core and NS5A) has been shown to induce accumulation of intracytoplasmic triglyceride rich droplets. ${ }^{9}$

There are several identified mechanisms whereby HCV may alter lipid metabolism. Firstly, HCV core protein has been shown to directly inhibit the function of microsomal triglyceride transfer protein, a major regulator of hepatic assembly, and secretion of nascent triglyceride rich very low density lipoproteins (VLDL). The latter effect impairs the ability of hepatocytes to assemble and secret VLDL. ${ }^{10}{ }^{11}$ Secondly, HCV core protein has been observed to induce mitochondrial injury resulting in oxidative stress. Oxidative stress perturbs lipid peroxidation, thereby contributing to the development of steatosis. ${ }^{12-14}$ Finally, microarray studies have illustrated the ability of HCV (in particular genotype 3) to induce transcription of several genes involved in lipid metabolism in the liver. ${ }^{15}{ }^{16}$ Among these is stearoyl coenzyme A desaturase 4 (SCD4), a rate limiting enzyme in the synthesis of monounsaturated fats. ${ }^{15}$ Reduced expression of SCD4 in livers of ob/ob mice has been shown to significantly ameliorate hepatic steatosis. ${ }^{17}$

\section{INSULIN RESISTANCE AND STEATOSIS IN HCV INFECTED PATIENTS}

Steatosis in patients with genotype 1 infection is increasingly recognised as a component of the metabolic syndrome, a condition invariably associated with IR. In support, host factors such as age, body mass index (BMI), and central obesity, have been shown to correlate with the development of steatosis in genotype 1 infected patients (but not genotype 3). ${ }^{18}$ Fartoux and colleagues ${ }^{2}$ have further demonstrated that HOMA IR was the only risk factor independently associated with the development of steatosis in genotype 1 infected patients $(\mathrm{p}=0.001)$. Moreover, the degree of steatosis was significantly predictive of HOMA IR $(\mathrm{p}=0.004)$.

There are several uncertainties regarding the cascade of events leading to the development of IR and steatosis in HCV infected patients with features of the metabolic syndrome. As such, whether IR or steatosis is the primary or secondary event in these patients is unclear.

Overall, there are sufficient clinical and experimental data indicating that excess fat can perpetuate IR: large epidemiological studies reveal that the risk of IR rises as body fat content (determined by BMI) increases, from the very lean to the very obese. ${ }^{19}$ Experimental evidence also indicates that intracellular accumulation of fatty acid metabolites (either through increased delivery or decreased metabolism) in the liver or muscle directly promotes serine phosphorylation (in contrast with tyrosine phosphorylation) of insulin receptor substrate l (IRS-1). This effect leads to impaired glucose transport activity and other events downstream of insulin receptor signalling. ${ }^{20}$ In this respect, measures to reduce circulating free fatty acid and liver triglyceride content have been shown to restore insulin signalling and reverse both hepatic and muscle IR induced by high fat diets. ${ }^{17} 21$

Another common link in the development of IR and steatosis is the adipocyte secreted proteins leptin and adiponectin. Leptin is a protein product of the adipocyte obese $(o b)$ gene. Serum leptin levels have been observed to be increased in patients with NASH and chronic HCV infection. ${ }^{22}{ }^{23}$ Moreover, in each of these diseases, serum leptin level has been reported to independently correlate with hepatic steatosis. ${ }^{22} 24$ While it is recognised that the effect of leptin on insulin sensitivity is variable, increased expression of leptin in hepatocytes has been shown to attenuate several insulin induced activities, including tyrosine phosphorylation of IRS- $1 .{ }^{25}$

Adiponectin is abundantly synthesised and secreted by adipose tissue. Serum levels of adiponectin correlate with systemic insulin sensitivity. More recently, low levels of serum adiponectin have been shown to correlate with the presence of steatosis in patients with chronic HCV infection. The latter observation suggests a role for adiponectin in the development of IR and steatosis in these patients. ${ }^{26}$

In contrast with the effect of fat on IR, insulin itself controls the regulation of a host of genes involved in lipid metabolism. ${ }^{27}$ The ability of insulin to activate lipogenesis is partly mediated by inducing the transcription of the sterol regulatory element binding protein lc (SREBP-1C), a key regulator of fatty acid synthesis in the liver. The effect of insulin on SREBP-1c transcription is even more apparent in the presence of profound $\mathrm{IR}^{28}$ In this setting, obese animals with IR have increased levels of SREBP-1c resulting in increased rates of fatty acid synthesis and the development of hepatic steatosis. $^{2930}$ Subsequent normalisation of SREBP-1 expression in these animals dramatically ameliorates steatosis. ${ }^{28}$

\section{HCV AND INSULIN RESISTANCE}

Several studies (including that of Fartoux and colleagues ${ }^{2}$ ) evaluating IR in patients with chronic HCV infection have found that the development of IR can occur early in the course of the disease. This effect appears to be independent of body weight, stage of liver disease, and presence or absence of overt diabetes. ${ }^{31-33}$ There are other clinical observations supporting a "fat independent" mechanism in the development of IR in HCV infected patients. Firstly, Fartoux and colleagues ${ }^{2}$ and others $^{32}$ have observed that patients infected with HCV genotype 3 have more extensive hepatic steatosis but a lower incidence of IR. ${ }^{32}$ This observation supports a genotype specific mechanism underlying IR in HCV infected patients. $^{32}$ Secondly, two studies demonstrated that clearance of $\mathrm{HCV}$ with antiviral therapy resulted in restoration of insulin sensitivity and euglycaemia. $^{34}{ }^{35}$ Finally, the extent of IR has been shown to correlate with the 


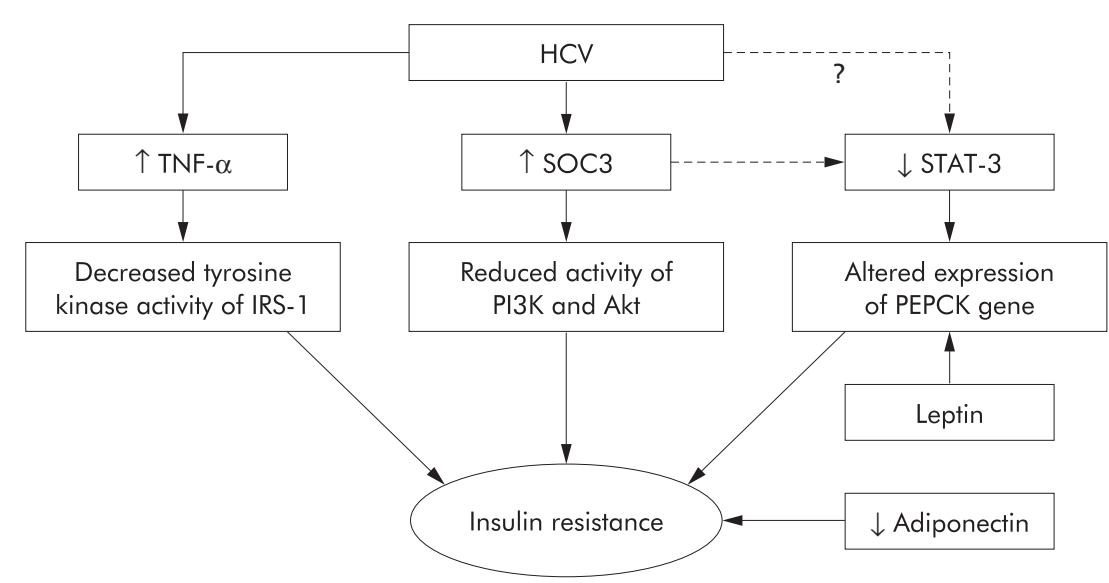

Figure 1 Molecules that are likely to be involved in mediating insulin resistance (IR) in hepatitis $C$ virus (HCV) infection. Tumour necrosis factor $\alpha(\mathrm{TNF}-\alpha)$ is increased in the serum and liver of HCV infected patients. TNF induces IR by decreasing the tyrosine kinase activity of insulin receptor substrate 1 (IRS-1). ${ }^{39}$ Treatment of HCV core transgenic mice with anti-TNF- $\alpha$ has been shown to restore insulin sensitivity. High levels of suppressor of cytokine signalling 3 (SOC3) have been detected in association with IR in HCV infection. This effect was associated with reduced insulin induced phosphorylation of the p85 subunit of phosphatidylinositol 3-kinase (PI3K) and Akt. ${ }^{37}$ SOC3 (and possibly HCV) can attenuate the activity of signal transducer and activator of transcription 3 (STAT-3). Mice lacking STAT-3 specifically in the liver have been reported to exhibit IR and, when fed a high fat diet, glucose intolerance. The latter was associated with increased expression of the phosphoenolpyruvate carboxykinase (PEPCK) gene. ${ }^{38}$ The PEPCK gene itself is a target for leptin (also increased in HCV infection) mediated regulation of gluconeogenesis in the liver. Finally, reduced expression of adiponectin is associated with obesity and IR. Low serum levels of adiponectin have been shown to correlate with steatosis in $\mathrm{HCV}$ infected patients. ${ }^{26}$

grade of portal inflammation in $\mathrm{HCV}$ infected patients. ${ }^{32}$ Collectively, these data suggest that either HCV per se or the inflammatory response incited by HCV in the liver is central to the development of IR. This first hypothesis has been recently verified in HCV core transgenic mice, observed to develop IR resistance as early as one month of age, in the absence of either overt liver injury or excessive body weight gain.

The precise mechanisms whereby HCV induces IR remain elusive but recent progress has shed light on several critical pathways. Impairment of IRS-1 and IRS-2 expression has been observed in the livers of both HCV infected patients as well as in HCV core transgenic mice. ${ }^{36}{ }^{37}$ Specifically, HCV core protein has been shown to inhibit insulin induced phosphorylation of the p85 subunit of phosphatidylinositol 3-kinase (PI3K) and Akt, which are downstream components of IRS in the liver. ${ }^{37}$ Interestingly, $\mathrm{HCV}$ has been reported to mediate dysfunction of the insulin signalling pathways by upregulating the expression of suppressor of cytokine signalling 3 (SOC 3$).{ }^{37}$ This observation is quite important in light of recent data demonstrating direct involvement of SOCl and SOC3 in regulating expression of SREBP-1c in the livers of obese animals. ${ }^{38}$ In these animal models, overexpression of SOCl and SOC3 proteins has been shown to enhance SREBP-lc promoter activity by attenuating signal transducer and activator of transcription 3 (STAT-3) mediated inhibition of this region. ${ }^{38}$ The net effect in these animals was development of systemic IR and hepatic steatosis. Conversely, inhibiting expression of SOCs protein in obese animals normalised levels of SREBP-1 and improved insulin sensitivity and hepatic steatosis. Consistent with these data, hepatic STAT-3 signalling has recently been shown to be essential for normal glucose homeostasis and insulin sensias HCV is recognised as influencing the activity of STAT-3. It is therefore intriguing to speculate that STAT-3 may be one of the key molecules involved in HCV mediated IR (fig l).

\section{ROLE OF CYTOKINES}

Tumour necrosis factor $\alpha$ (TNF- $\alpha$ ) levels are elevated in the liver and serum of patients with chronic HCV infection. development of IR through interfering with insulin signalling. ${ }^{40}$ In IR HCV core transgenic mice, treatment with antiTNF- $\alpha$ restored insulin sensitivity, thus supporting the notion that TNF- $\alpha$ is a major factor for the development of IR in HCV infection. ${ }^{31}$

\section{ROLE OF STEATOSIS AND INSULIN RESISTANCE IN PROGRESSION OF HCV LIVER DISEASE}

In agreement with previous reports, ${ }^{34741}$ Fartoux and colleagues ${ }^{2}$ tivity. ${ }^{39}$ These observations are relevant TNF- $\alpha$ plays an important role in the observed an association between steatosis and severity of fibrosis, irrespective of HCV genotype. While insulin levels were predictive of fibrosis in their univariate analysis, subsequent multivariate analysis confirmed steatosis, but not insulin levels, to be independently associated with fibrosis $(p=0.02)$.

Thus two keys questions arise: is fat per se fibrogenic and what is the role of insulin in the fibrotic process?

Steatosis is associated with increased production of reactive oxygen species which initiate lipid peroxidation, resulting in hepatic stellate cell activation. ${ }^{42}$ However, in NASH, disease progression is recognised as being slower than that observed in patients with HCV infection and steatosis. Thus it is likely that the coexistence of HCV and steatosis aggravates and accelerates the injury induced by each alone. In this setting, hepatic inflammation induced by the host response, together with the increased production of several proinflammatory and profibrotic cytokines, provide the substrate for the "second hit" in the steatotic liver. Also, the ability of the virus itself to induce oxidative stress and promote lipid peroxidation may further aggravate the pathogenic process induced by steatosis. Consider also that fat may render HCV infected liver more vulnerable to injury. Livers with steatosis are more sensitive to TNF- $\alpha$ mediated inflammation and liver injury. ${ }^{43}$ Moreover, in HCV livers with steatosis, apoptosis activity has been noted to be increased compared with infected livers without steatosis. ${ }^{44}$

While Fartoux and colleagues ${ }^{2}$ could not find a direct association between IR and fibrosis, others have. ${ }^{32} 33$ The authors do concede that insulin plays a significant role in the development of fibrosis via a mechanism involving steatosis. In this regard, steatosis promotes cellular IR which, in turn, induces compensatory hyperinsulinaemia. Hyperinsulinaemia has been shown to directly stimulate hepatic stellate cell proliferation and increase expression of connective tissue growth factor, a key factor in the progression of fibrosis. ${ }^{46}$ Collectively, the data implicate both steatosis and IR in liver disease progression in HCV infected patients.

\section{CONCLUSIONS}

Our knowledge of the mechanisms and significance of steatosis and IR in patients with chronic HCV infection has advanced. The work by Fartoux and colleagues ${ }^{2}$ adds to the growing evidence that the relationship between HCV, steatosis, and IR is genotype specific and that steatosis and IR are closely linked to the progression of liver disease in HCV infected patients. As 
such, we need to clarify the molecular pathways involved in mediating these inter-relationships. In light of our current knowledge of the implications of steatosis and IR in liver disease, the importance of lifestyle changes (such as weight loss) need to be an emphasised in treating HCV infected patients. Similarly, new therapeutic approaches exploiting the interaction between HCV and lipid metabolism are eagerly awaited.

\section{ACKNOWLEDGEMENTS}

This work was supported by a grant from NIH, 2ROI DK053792.

Gut 2005;54:903-906

doi: 10.1136/gut.2004.059873

\section{Authors' affiliations}

A Zekry, J G McHutchison, A M Diehl,

Division of Gastroenterology and Duke Clinical Research Institute, Duke University Medical Centre, Durham, North Carolina, USA

Correspondence to: $\operatorname{Dr}$ A M Diehl, Gastroenterology Division, Duke University, Snyderman Building, GSRB-1, Suite 1073, Box 3256, 595 LaSalle St, Durham, NC 27710, USA; diehl004@mc.duke.edu

Conflict of interest: None declared.

\section{REFERENCES}

1 Goodman ZD, Ishak KG. Histopathology of hepatitis $C$ virus infection. Sem Liver Dis 1995; 15:70-81

2 Fartoux L, Poujol-Robert A, Guéchot J, et al. Insulin resistance is a cause of steatosis and fibrosis progression in chronic hepatitis C. Gut 2005;54:1003-8

3 Kumar D, Farrell GC, Fung C, et al. Hepatitis C virus genotype 3 is cytopathic to hepatocytes: Reversal of hepatic steatosis after sustained therapeutic response. Hepatology 2002;36:1266-72.

4 Adinolfi LE, Gambardella M, Andreana A, et al. Steatosis accelerates the progression of liver damage of chronic hepatitis $\mathrm{C}$ patients and correlates with specific HCV genotype and visceral obesity. Hepatology 2001;33:1358-64.

5 Rubbia-Brandt L, Quadri R, Abid K, et al. Hepatocyte steatosis is a cytopathic effect of hepatitis $C$ virus genotype 3 . J Hepatol 2000;33:106-15.

6 Poynard T, Ratziu V, McHutchison J, et al. Effect of treatment with peginterferon or interferon alfa$2 \mathrm{~b}$ and ribavirin on steatosis in patients infected with hepatitis C. Hepatology 2003;38:75-85.

7 Patton HM, Patel K, Behling C, et al. The impact of steatosis on disease progression and early and sustained treatment response in chronic hepatitis C patients. J Hepatol 2004;40:484-90.

8 Hui JM, Kench J, Farrell GC, et al. Genotypespecific mechanisms for hepatic steatosis in chronic hepatitis C infection. J Gastroenterol Hepatol 2002;17:873-81.

9 Moriya K, Yotsuyanagi H, Shintani $\mathrm{Y}$, et al. Hepatitis $C$ virus core protein induces hepatic steatosis in transgenic mice. J Gen Virol 1997;78: 1527-31.

10 Perlemuter G, Sabile A, Letteron P, et al. Hepatitis $C$ virus core protein inhibits microsomal triglyceride transfer protein activity and very low density lipoprotein secretion: a model of viralrelated steatosis. FASEB J 2002;16:185-94.

11 Serfaty L, Andreani T, Giral P, et al. Hepatitis C virus induced hypobetalipoproteinemia: a possible mechanism for steatosis in chronic hepatitis C. J Hepatol $2001 ; 34: 428-34$.

12 Okuda M, Li K, Beard MR, et al. Mitochondria injury, oxidative stress, and antioxidant gene expression are induced by hepatitis $C$ virus cor protein. Gastroenterology 2002;122:366-75.

13 Moriya K Fujie $H$, Shintani $Y$, et al. The core protein of hepatitis $C$ virus induces hepatocellular carcinoma in transgenic mice. Nat Med 1998;4:1065-7.

14 Lerat $\mathbf{H}$, Honda $M$, Beard MR, et al. Steatosis and liver cancer in transgenic mice expressing the structural and nonstructural proteins of hepatitis $C$ virus. Gastroenterology 2002;122:352-65.

15 Bigger CB, Guerra B, Brasky KM, et al. Intrahepatic Gene Expression during Chronic Hepatitis C Virus Infection in Chimpanzees. J Virol 2004;78: 13779-92.

16 Shackel NA, McGuinness PH, Abbott CA, et al. Insights into the pathobiology of hepatitis $C$ virusassociated cirrhosis: analysis of intrahepatic differential gene expression. Am J Pathol 2002; 160:641-54.

17 Sekiya M, Yahagi N, Matsuzaka T, et al. Polyunsaturated fatty acids ameliorate hepatic steatosis in obese mice by SREBP-1 suppression. Hepatology 2003;38:1529-39.

18 Adinolfi LE, Utili R, Ruggiero G. Body composition and hepatic steatosis as precursors of fibrosis in chronic hepatitis $C$ patients. Hepatology 1999;30:1530-1.

19 Colditz GA, Willett WC, Rotnitzky A, et al. Weight gain as a risk factor for clinical diabetes mellitus in women. Ann Intern Med 1995; 122:481-6.

20 Shulman GI. Cellular mechanisms of insulin resistance. J Clin Invest 2000;106:171-6.

21 An J, Muoio DM, Shiota M, et al. Hepatic expression of malonyl-CoA decarboxylase reverses muscle, liver and whole-animal insulin resistance. Nat Med 2004;10:268-74.

22 Chitturi S, Farrell G, Frost L, et al. Serum leptin in NASH correlates with hepatic steatosis but not fibrosis: a manifestation of lipotoxicity? Hepatology 2002;36:403-9.

23 Patel K, Muir A, McHutchison JG, et al. A link between leptin and steatosis in chronic hepatitis C? Time to weigh up the fats. Am J Gastroenterol 2003;98:952-5

24 Romero-Gomez M, Castellano-Megias VM, Grande $\mathrm{L}$, et al. Serum leptin levels correlate with hepatic steatosis in chronic hepatitis $C$ Am J Gastroenterol 2003;98: 1 135-41.

25 Cohen B, Novick D, Rubinstein M. Modulation of insulin activities by leptin. Science 1996;274: 1185-8.

26 Michel PJ, Anne M, Valerie J, et al. Decreased plasma adiponectin concentrations are closely related to steatosis in HCV-infected patients. J Clin Endocrinol Metab, 2005 not on $\mathrm{p} / \mathrm{m}^{*}$

27 Shimomura I, Matsuda M, Hammer RE, et al Decreased IRS-2 and increased SREBP-1 c lead to mixed insulin resistance and sensitivity in livers of lipodystrophic and ob/ob mice. Mol Cell 2000;6:77-86.

28 Shimomura I, Shimano H, Korn BS, et al. Nuclear sterol regulatory element-binding proteins activate genes responsible for the entire program of unsaturated fatty acid biosynthesis in transgenic mouse liver. J Biol Chem 1998;273:35299-306.
29 Yahagi N, Shimano H, Hasty AH, et al. Absence of sterol regulatory element-binding protein-1 (SREBP-1) ameliorates fatty livers but not obesity or insulin resistance in Lep(ob)/Lep(ob) mice. J Biol Chem 2002;277:19353-7.

30 Horton JD, Shimomura I, Ikemoto S, et al. Overexpression of sterol regulatory elementbinding protein-la in mouse adipose tissue produces adipocyte hypertrophy, increased fatty acid secretion, and fatty liver. $J$ Biol Chem 2003;278:36652-60

31 Shintani Y, Fujie $\mathrm{H}$, Miyoshi $\mathrm{H}$, et al. Hepatitis $\mathrm{C}$ virus infection and diabetes: direct involvement of the virus in the development of insulin resistance. Gastroenterology 2004; 126:840-8.

32 Hui JM, Sud A, Farrell GC, et al. Insulin resistance is associated with chronic hepatitis $C$ virus infection and fibrosis progression[corrected]. Gastroenterology 2003;125:1695-704.

33 Petit JM, Bour JB, Galland-Jos C, et al. Risk factors for diabetes mellitus and early insulin resistance in chronic hepatitis C. J Hepatol 2001;35:279-83.

34 Tanaka H, Shiota G, Kawasaki H. Changes in glucose tolerance after interferon-alpha therapy in patients with chronic hepatitis C. J Med 1997;28:335-46.

35 Konrad T, Zeuzem S, Vicini $P$, et al. Evaluation of factors controlling glucose tolerance in patients with HCV infection before and after 4 months therapy with interferon-alpha. Eur J Clin Invest 2000;30:111-21.

36 Aytug S, Reich D, Sapiro LE, et al. Impaired IRS1/PI3-kinase signaling in patients with HCV: a mechanism for increased prevalence of type 2 diabetes. Hepatology 2003;38:1384-92.

37 Kawaguchi T, Yoshida T, Harada $M$, et al. Hepatitis $C$ virus down-regulates insulin recepto substrates 1 and 2 through up-regulation of suppressor of cytokine signaling 3. Am J Pathol 2004;165: 1499-508.

38 Ueki K, Kondo T, Kahn CR. Suppressor of cytokine signaling 1 (SOCS-1) and SOCS-3 cause insulin resistance through inhibition of tyrosine phosphorylation of insulin receptor substrate proteins by discrete mechanisms. Mol Cell Biol 2004;24:5434-46.

39 Inove H, Ogawa W, Ozaki M, et al. Role of STAT-3 in regulation of hepatic gluconeogenic genes and carbohydrate metabolism in vivo. Nat Med 2004; 10:168-74.

40 Hotamisligil GS, Murray DL, Choy LN, et al. Tumor necrosis factor alpha inhibits signaling from the insulin receptor. Proc Natl Acad Sci U S A 1994:91:4854-8.

41 Hourigan LF, Macdonald GA, Purdie D, et al Fibrosis in chronic hepatitis $C$ correlates significantly with body mass index and steatosis. Hepatology 1999;29:1215-9.

42 Chavin KD, Yang S, Lin HZ, et al. Obesity induces expression of uncoupling protein-2 in hepatocytes and promotes liver ATP depletion. J Biol Chem 1999;274:5692-700.

43 Yang $S Q$, Lin $H Z$, Lane $M D$, et al. Obesity increases sensitivity to endotoxin liver injury: implications for the pathogenesis of steatohepatitis. Proc Natl Acad Sci U S A 1997;94:2557-62.

44 Walsh MJ, Vanags DM, Clouston AD, et al. Steatosis and liver cell apoptosis in chronic hepatitis C: a mechanism for increased liver injury. Hepatology 2004;39:1230-8.

45 McCaughan GW, George J. Fibrosis progression in chronic hepatitis $C$ virus infection. Gut 2004:53:318-21.

46 Paradis V, Perlemuter G, Bonvoust F, et al. High glucose and hyperinsulinemia stimulate connective tissue growth factor expression: a potential mechanism involved in progression to fibrosis in nonalcoholic steatohepatitis. Hepatology 2001;34:738-44 